\title{
Modeling Assessment on Technological Challenges Facing Small-Scale Gold Miners in Tanzania and How Engineering Could Solve Them
}

\author{
Mtaita Charles Mtoni \\ Department of Built Environment Engineering, Mbeya University of Science and Technology, Mbeya, Tanzania \\ Email address: \\ mtaijunior@yahoo.com \\ To cite this article: \\ Mtaita Charles Mtoni. Modeling Assessment on Technological Challenges Facing Small-Scale Gold Miners in Tanzania and How \\ Engineering Could Solve Them. American Journal of Engineering and Technology Management. Vol. 2, No. 6, 2017, pp. 93-97. \\ doi: 10.11648/j.ajetm.20170206.14
}

Received: February 8, 2017; Accepted: February 24, 2017; Published: December 11, 2017

\begin{abstract}
This paper aims on assessing the effects associated to the challenges facing small-scale miners in Tanzania. Small scale mining in Tanzania is characterized by low productivity which is mainly a result of application of rudimentary and inappropriate technology which in turn impact on capacities to generate income. The choice of technology among small scale miners is largely influenced by the lack of capital. In order to get gold, small scale miners typically have to excavate the earth and extract gold rich ores, pull the ores from the pits, carry them to the crushing machine, crush them, sieve the sand and lastly extract gold from the sand by using mercury. Each of the stages mentioned above involve a ton of technological challenges which, if solved could improve productivity and subsequently the lives of small scale miners in the country. However, this study focuses on the costs of that economic growth in gold production over small-scale miners. It is estimated that in the early 1990s, Small-Scale Mining in gold accommodated around 400,000 people in Tanzania. Due to a lack of hard data, this study was based on mostly qualitative fieldwork in Chunya district, Mbeya region, Tanzania. The research investigates how technological challenges can affect small-scale gold miner's livelihood, focusing on those who depend, or have depended only on small-scale mining activities.
\end{abstract}

Keywords: Small-Scale Miners, Gold, Mining and Challenges

\section{Introduction}

Small scale mining in Tanzania is characterized by low productivity which is mainly a result of application of rudimentary and inappropriate technology which in turn impact on capacities to generate income. Is the kind of mining which involves the use of local or rudimentary hand tools such as hoes, panga, spades, buckets, etc in mining and processing of minerals. There are many possible methods to recover gold from ores; these include amalgamation, gravity concentration, leaching and flotation. This work focuses only amalgamation using mercury, a method that is on its onset application by smallscale gold miners in Tanzania. (Figure 1).

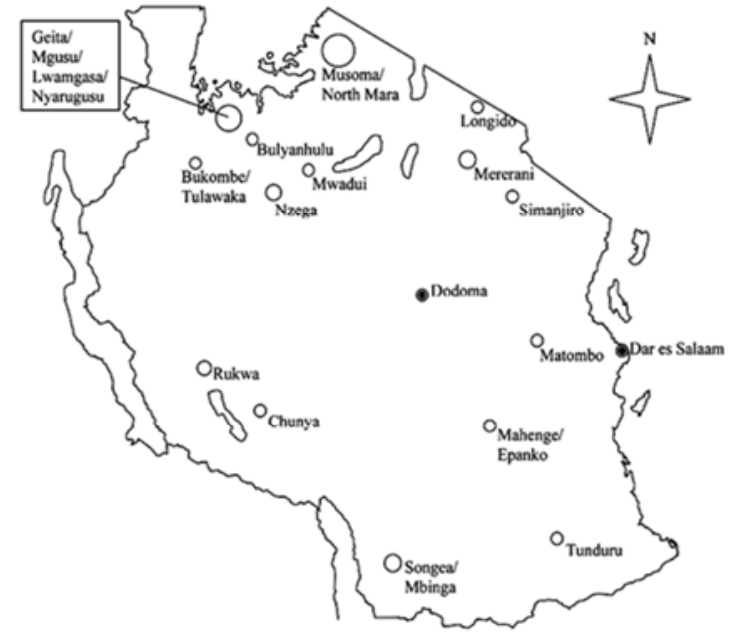

Figure 1. Various areas where mining activities are carried out in Tanzania. 


\section{Background of Minerals Deposit in Tanzania}

Tanzania is endowed with vast mineral resources [1]. These minerals are divided into five groups as: - metallic minerals include gold, iron ore, nickel, copper, cobalt and silver. Gemstones include diamond, tanzanite, ruby, and garnets. The industrial minerals include limestone, soda ash, gypsum, salt and phosphate [1]. Energy source Minerals, such as coal and uranium. And Construction minerals, such as aggregates, gravel, sand and dimension stones. The Tanzania Investment Report (2004) indicates that since 1999 the mining sector has become the dominant sector in Foreign Direct Investment (FDI) attraction. Investments in the mining sector are substantial and accounted for $34 \%$ of total FDI stock in 1999 and 40\% in 2009 [2]. The above paragraph is summarised in the following figure 2 .

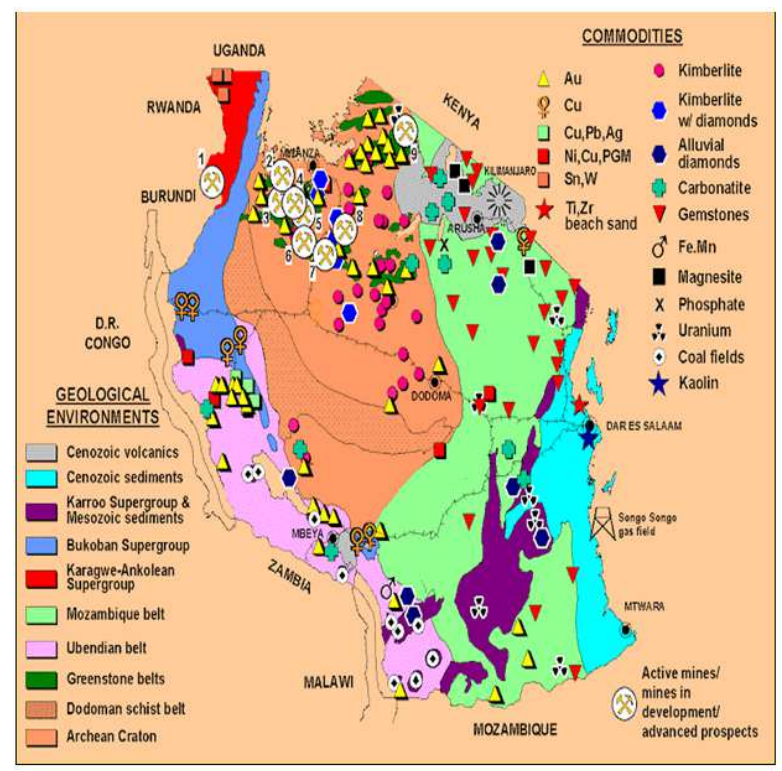

Figure 2. Tanzania's Endowment with Vast Minerals, Source: MEM.

\section{Design and Methods}

Study was conducted in Tanzania and concentrated at Chunya district, Mbeya region. Which is made up of population 290,478 where by $50.1 \%$ are male and $49.9 \%$ are female according to 2012 Tanzania National Census. The number of villages is estimated to be 73 . The choice of Chunya was based on the fact that the mine has many incidences related to challenges facing the small-scale miners. Nowadays the effect on challenges facing small-scale miners has been catching the eye of many headlines in the Newspapers, TVs and radios.

In the course of this study both primary and secondary data were collected. I conducted interviews, observations and focus group discussions with small-scale miners, local people from the village and village leaders in order to obtain the required data.

\subsection{The Interview Method}

The interview method was useful throughout fieldwork provided opportunity for a researcher to clear doubt from interviewees. The semi-structured interview was applied because of its flexibility which allowed the researcher to ask new questions while continuing with normal interviews and well-matched the nature of effects when discussing technological challenges linking to their operation. Snowballing non-probability sampling procedure was applied is selecting respondent where by a researcher started with the chairperson of the village.

\subsection{Observation Method}

The observation was useful throughout field work provided opportunity for a researcher to see what was happening and to take photo as a reference data from observation.

\subsection{The Focus Group Discussion}

The Focus Group Discussions (FGD) was more useful. The FGD started with few but later on attracted many People who positively participated. The FGD helped to get general views of the challenges small scale miners experiencing during their operation. The study shows that people feel free to discuss their challenges which supplemented with specific stories that related to the topic.

\section{Results}

Table 1 shows the Gross Domestic Product (GDP) and Employment Contribution by Mining Sector. After the economic reforms of the 1990s, the mining sector has been growing at the rate above 10 per cent; in 2000 the sector grew by 14.3 per cent reaching its highest peak of 17.1 in 2003, then slowed down to $10.7 \%$ in 2007 and then dwindled to the lowest rate ever of 1.2 per cent in 2009 due to the global financial crisis [3].

Despite this impressive growth, the sectors' contribution to the GDP has been below 10 per cent and therefore contributed to less than 5 per cent of all employment generated in the country, this is contrary to what is anticipated by the 1997 Mineral Policy [1]. However, as seen in Table 1, the sector contribution to the GDP is still increasing except for few years. The sector also contributes to 35 per cent of all exports earnings and currently is a major foreign exchange contributing sector. $[3,5]$.

Table 1. The Contribution of the Mining sector in the National Economy (2000 -2009).

\begin{tabular}{|c|c|c|c|c|c|c|c|c|c|c|}
\hline Year & 2000 & 2001 & 2002 & 2003 & 2004 & 2005 & 2006 & 2007 & 2008 & 2009 \\
\hline GDP Contribution (\%) & 1.6 & 1.8 & 2.1 & 2.4 & 2.6 & 2.9 & 3.2 & 3.6 & 3.4 & 3.3 \\
\hline Growth of the Sector $(\%)$ & 14.3 & 13.9 & 16.9 & 17.1 & 16.0 & 16.1 & 15.6 & 10.7 & 2.5 & 1.2 \\
\hline Employment to Tanzanians (in millions) & 0.75 & 0.8 & 0.85 & 0.95 & 1.1 & 1.2 & 1.3 & 1.38 & 1.38 & 1.4 \\
\hline
\end{tabular}

Source: URT, 2009 
In terms of employment, contribution is still low but its contribution has been increasing from 0.75 million in 2000 to 1.38 million in 2007 before the crisis, hence the sector is not in the list of top 3 employers despite the large scale investments, huge export values and incentives offered. The information and statistics shown below brings about questions on whether Tanzania is really benefiting this highly growing sector. (Figure 3).

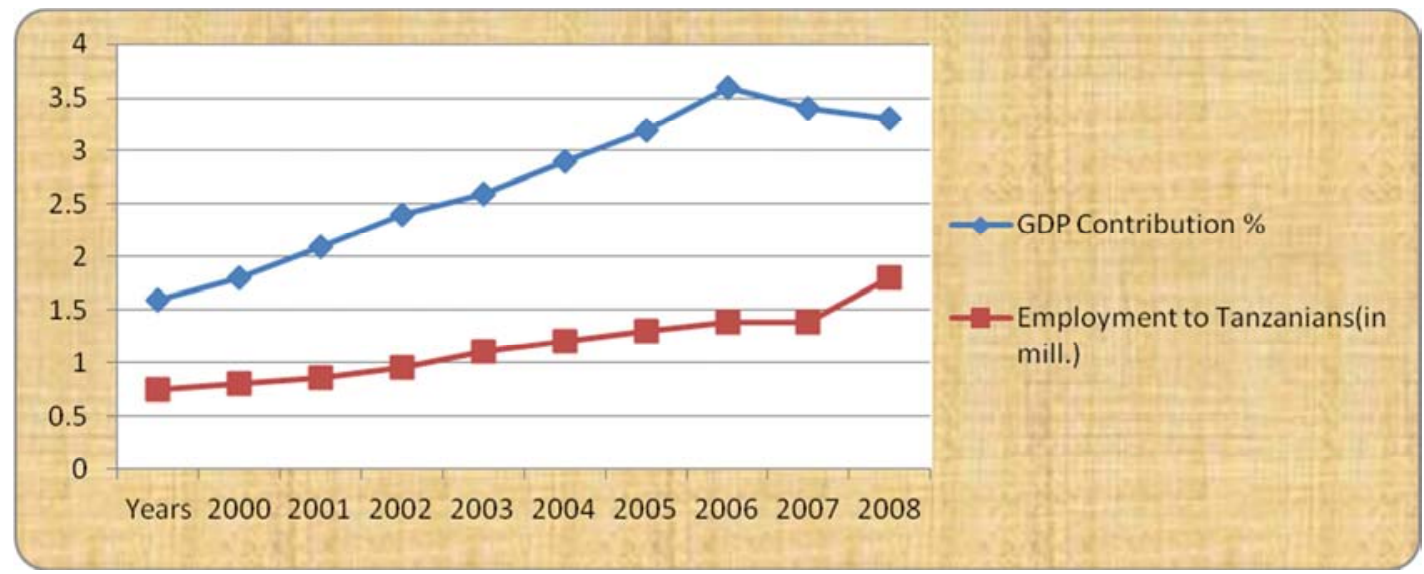

Figure 3. Trend in GDP and Employment Contribution by Mining Sector for 2000 - 2008, Source: URT, 2009.

Table 2 shows the Capita income for Tanzania Mainland Region. These regions are overwhelmed with high poverty rate. What surprises from the data is that the highest per capital incomes are from regions which do not produce gold such as Dar es Salaam, Kilimanjaro and Iringa; this implies that the mining sector has little contribution to national growth and poverty alleviation in Tanzania. As indicated in Table 2 Mbeya region (Chunya) has a low per capita income.

Table 2. Per Capital Income for Tanzania Mainland Regions in 2010 (in Tshs).

\begin{tabular}{llll}
\hline S/N & Regions & Per Capital Income & Rank \\
\hline 1 & Dodoma & 500,006 & 21 \\
2 & Arusha & 555,952 & 5 \\
3 & Kilimanjaro & 575,875 & 3 \\
4 & Shinyanga & 433,166 & 17 \\
5 & Tanga & 455,712 & 6 \\
6 & Morogoro & 537,032 & 8 \\
7 & Pwani & 455,607 & 15 \\
8 & Dar es Salaam & 834,978 & 1 \\
9 & Lindi & 494,104 & 13 \\
10 & Mtwara & 460,840 & 14 \\
11 & Ruvuma & 572,028 & 4 \\
12 & Iringa & 594,449 & 2 \\
13 & Mbeya & 554,023 & 7 \\
14 & Singida & 508,812 & 19 \\
15 & Tabora & 443,886 & 16 \\
16 & Rukwa & 521,927 & 10 \\
17 & Kigoma & 406,359 & 20 \\
18 & Kagera & 426,773 & 18 \\
19 & Mwanza & 509,577 & 12 \\
20 & Mara & 529,894 & 9 \\
21 & Manyara & 513,894 & \\
22 & Tanzania Mainland & 520,044 & \\
\hline
\end{tabular}

Gold Mining Process

The study reveals that, more than $90 \%$ of small scale gold miners use the same level of technology which is poor in extracting gold. This challenge has led to the complaints of not getting profits.

\section{Discussion}

\subsection{Mining}

Gold encased in rocks is usually mined by excavation. In many times, the visual inspection has led to fraudulent conclusions which lower productivity. Small scale miners commonly use non-mechanized tools (shovels, hoes, picks and wheelbarrows) for excavation, which makes the process unnecessarily slow and labor intensive. Lack and/or poorly performing equipment such as compressors and protection gears have exposed numerous small-scale miners to respiratory related diseases.

\subsection{Transport of the Ore (Haulage System)}

After being mined, the ore need to be transported from underground to the surface and subsequently to the crushing machines. Small-scale miners rely on human labor; the materials used mostly include sacks, logs, ropes, buckets and sometimes iron bars. To haul the ores from underground, small scale miners usually use either a bag or gallon fastened to a rope (hoisting system); two people assist each other to pull out the load from the pit by rolling. Another person is always inside the pit whose major purpose is to load the bag or gallon with the ore. The rope is lowered and hauled by means of a local simple pulley system. Using this system needs a lot of human capital as well as unnecessarily expense of time. Typically, a team of 20 people can haul not more than 20 bags of ore from $100 \mathrm{~m}$ underground to the surface. After it has been hauled, the ore needs to be transported to the crushing machines, which is also done by human labor. (Figure 4) 


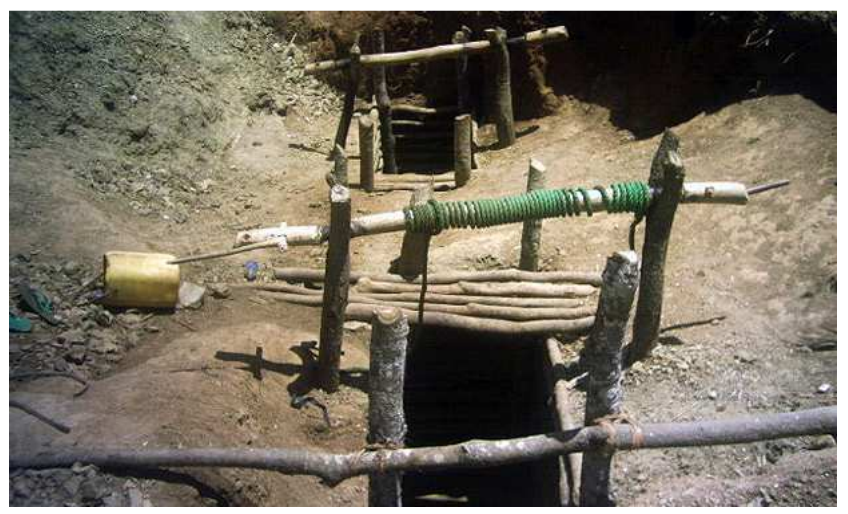

Figure 4. Haulage by using local simple pulley system, source MEM.

\subsection{Crushing and Grinding}

The commonly crushers used by small scale miners allow two bags (about $100 \mathrm{~kg}$ ) of ores and run on petro oils or fuels. New crushers usually take a minimum of 30 minutes; therefore the amount of crushed and ground ore per day is limited.

\subsection{Leaching}

A finely ground powder is then forced by water over the washing table covered by a beaten cotton sac. Being denser than other materials in the powder, gold will leach to the cotton sac and be recovered on later stages. The recovery of gold using this method is very poor, usually $30 \%$, the other $70 \%$ going unrecovered as gold tailings. (Figure 5).

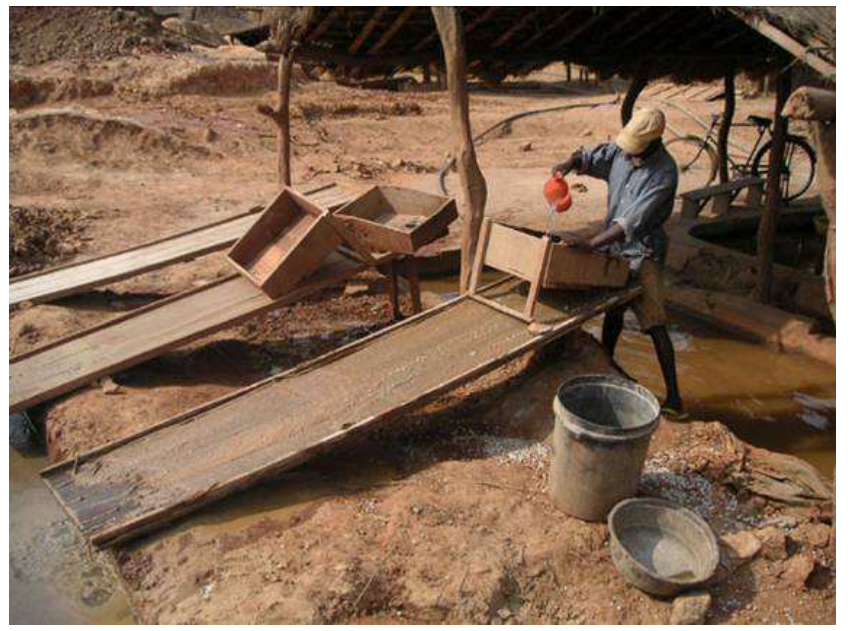

Figure 5. Small scale miner is recovering gold by leaching process, source: MEM.

\subsection{Gold Recovery}

Small-scale miners continue to use mercury for the recovery of gold without taking any protective measures despite danger to human health and the environment. The attraction of mercury is based on the fact that it is readily available, cheap and efficient in recovering fine-grained gold. (Figure 6).

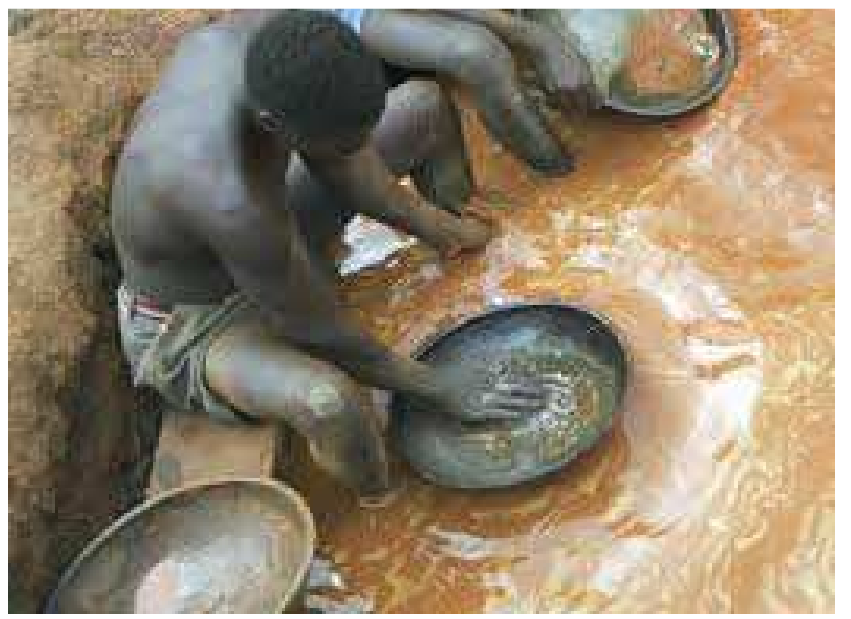

Figure 6. Small scale miners in Tanzania extracting gold by using mercury, source: Geocenter. dk.

\section{Conclusion}

The formulated analysis has shown a strong relationship between the challenges facing small scale gold miners and effects occurring in small-scale mining activities such as hazards, low production, low per capital income and poor National economy. Also risk that human health is encountered.

\section{Recommendations}

Under present technological conditions productivity, gold recovery and yields continue to be low and income remains at subsistence level. This hinders re-capitalization and advancement of mining operations and keeps small-scale miners in a vicious cycle of poverty. A major problem restraining access to technology by small-scale miners is lack of finance and appropriate information about where and how to procure equipment. In addition, there are few companies specialized in small scale mining equipment. There is a need to improve technological capacities. As it can be observed, processes involved in gold mining are modular and highly non-mechanized. Efforts should be made, especially in the miniaturization of large scale mining equipment into small and affordable to the majority of small scale miners. Efforts should be made to introduce small and affordable machines that can combine two or more processes thus increase efficiency. Surveys and mapping areas as well as zones with gold should be provided to small scale miners which will reduce their wild-hunting for gold, which is uneconomical Essentially, there is a need to create technologies that are more productive, flexible, affordable, reliable, acceptable, and simpler and cheaper that can foster the development of local competitive small to medium-scale enterprises.

Access to technology can also be facilitated by the establishment of communal centers, where centralized equipment and services could be provided to small-scale miners at discounted prices or through payment in kind.

All small scale mining activities should be registered and 
given sticker under supervision of professional mining engineer or recognized mining engineer as per ministry of energy and mineral resource requirement or mining engineers' registration body which currently does not exist yet. No small scale miner should be allowed to conduct mining activities without having stamp or certificate of professional mining engineer or recognized mining engineer.

\section{References}

[1] United Republic of Tanzania (URT), 2008 Tanzania mineral policy and Kitainda, 2010.

[2] United Republic of Tanzania (URT), Tanzania mineral policy 2010 .

[3] United Republic of Tanzania (URT), 2009 the Mineral Policy of Tanzania, Ministry of Energy and Minerals.

[4] Dreschler, B. (2001) 'Small-Scale Mining and Sustainable Development within the SADC'; Edited by International Institute for Environment and Development; England 2002.
[5] United Republic of Tanzania (URT), 1998: Tanzania Mineral Policy 1997: Financial Law Act 1997.

[6] Michelsen (2010) 'Contribution of Artisanal and Small-Scale Mining to Poverty Reduction in Tanzania', Department of International Development (UK) Denmark; World Development Vol; 38 No. 3, pp. 379-392; 2010 N-5892 Bergen, Norway.

[7] Masialeti, M (2004): Small-scale mining in Zambia, Department of Mining Engineering University of Zambia. Lusaka- Zambia.

[8] American Journal of Engineering, (2015) Technology and Society. Vol. 2, No. 6, pp. 162-166.

[9] Mbota Amani Mwikwabe (2011) The Sustainable Livelihood and Displacement: Case of Artisanal and Small-scale Gold miners.

[10] Ntalikwa J. (2015), Gold Recovery by Cyanide Leaching.

[11] Marco, K and Lu, Y (2010); Gold Mining Investment Incentives in Tanzania; Current Issues and the possible Remedies: International Journal of Business and Management. 